\title{
Volume Change Control of High Plasticity Clay by the Stabilization of Fine-grained Cements
}

\author{
Murat Mollamahmutoğlu ${ }^{1}$ Eyubhan Avcı², Altan Erdem ${ }^{3}$ \\ ${ }^{1}$ Faculty of Engineering, Gazi University \\ Ankara, Turkey \\ mmolla@gazi.edu.tr \\ ${ }^{2}$ Vocational School of Technical Science, Hitit University \\ Corum, Turkey \\ eyubhanavci@gmail.com \\ ${ }^{3}$ Doğuş Construction Group - Ayson Geotechnical \& Marine Construction Co. \\ İzmir, Turkey \\ altanerdem@gmail.com
}

\begin{abstract}
This paper presents the swelling potential and compressibility of high plasticity clayey soil stabilized with slag-based superfine cement (SSC), Portland-based microfine cement (PMC) and ordinary Portland cement (OPC). The swelling potential of high plasticity clayey soil is significantly reduced by PMC, SSC and OPC stabilizations. Increase in the contents of PMC, SSC and OPC further reduces the swelling potential of high plasticity clayey soil. While the most influential one among the stabilizers used in reducing the swelling potential of high plasticity clayey soil is PMC, SSC is the least effective one. The compressibility of high plasticity clayey soil is reduced ten, eleven and six times by OPC, PMC and SSC stabilizations respectively. Increase in OPC, PMC and SSC contents slightly decreases the compressibility of high plasticity clayey soil. The compressibility of SSC stabilized high plasticity clayey soil is slightly higher than those of OPC and PMC stabilized specimens. SSC stabilization is found to be the least effective one in reducing the compressibility of high plasticity clayey soil. In general, PMC stabilization is more effective than both SSC and OPC stabilizations in reducing both compressibility and swelling potential characteristics of high plasticity clayey soil.
\end{abstract}

Keywords: Clay stabilization, Cement types, Compressibility, Swelling

\section{Introduction}

Expansive soils containing minerals such as smectite clays are present throughout the world. Their pronounced characteristics are high plasticity, low strength, high swelling and shrinkage potentials. Due to these properties, they frequently bring about bearing capacity problems in structural foundations, infrastructures, highways and airfield pavements [1]. The cost of damage of expansive soils to structures is roughly calculated as $£ 150$ million in the UK, $\$ 1000$ million in the USA and many billions of ponds worldwide per year [2]. There are several methods to get rid of expansive soil's problems. Generally, these methods may be categorized as mechanical and chemical stabilizations. Lime, gypsum, cement, bottom and top fly ashes, are the main components used in chemical stabilization, which cause a chemical reaction in soil water system and finally stabilizes the soil.

Cement is one of the oldest and widely used methods in the stabilization of soils all over the world. It was stated that cement stabilization decreased the plasticity of soil and made it more workable [3]. Its compressive strength and load bearing characteristics were also improved by cement stabilization. Improvement of clayey soil properties result from soilcement reaction which produces primary and secondary cementitious materials in the soil-cement matrix. The primary cementitious materials are formed by hydration reaction and are comprised of hydrated calcium silicates, calcium aluminates, and hydrated lime [4]. A secondary pozzolanic reaction between the hydrated lime and the silica and alumina from the clay minerals leads to the formation of additional calcium silicate hydrates and calcium aluminate hydrates [5]. This soil-cement reaction provides a clear basis by which to explain the improvement of stabilized clayey soil. Several authors discussed the effect of cement stabilization regarding soil type and its plasticity, cement content, mixing and 
compaction methods, curing condition, particle size distribution and pulverization [6-15]. However, the effects of various types of cement having different chemical composition as well as particle size on the volumetric behaviour of high plasticity clayey soils are scarcely evaluated. Therefore, this research was mainly focused on the effect of cement types and their particle sizes on the consistency limits, compaction, swelling and compressibility characteristics of high plasticity clayey soil.

\section{Clayey soil}

Clayey soil used in this study was collected from Golbas1 region, Ankara, Turkey. A surficial organic soil layer of about $0.50 \mathrm{~m}$ was clearly removed and then disturbed samples were obtained through sample tubes from a depth of around $1.5 \mathrm{~m}$. Soil samples were then transported to the Geotechnical Laboratory of Gazi University. They were removed from the tubes and then broken into small pieces, spreaded over the floor and dried in an open air. The particle size distribution (Fig. 1), Atterberg limits, specific gravity and organic content of clayey soil were determined (Table 1) according to ASTM D 422-63 (2002), ASTM D 4318-10e1 (2010) and ASTM D 854-02 (2002), respectively [16-18]. Clayey soil was classified as high plasticity clay (Table 1) with respect to USCS [19].

Table 1: Clayey soil properties.

\begin{tabular}{|l|c|}
\hline Basic characteristics and description & Values \\
\hline Specific gravity & 2.80 \\
\hline Passing No. 200 sieve $(<0.075 \mathrm{~mm})(\%)$ & 98.6 \\
\hline Plastic limit (\%) & 32 \\
\hline Liquid limit (\%) & 104 \\
\hline Plasticity index (\%) & 72 \\
\hline Free Swell (\%) & 17.7 \\
\hline Soil class & $\mathrm{CH}$ \\
\hline Organic material (\%) & 2.29 \\
\hline
\end{tabular}

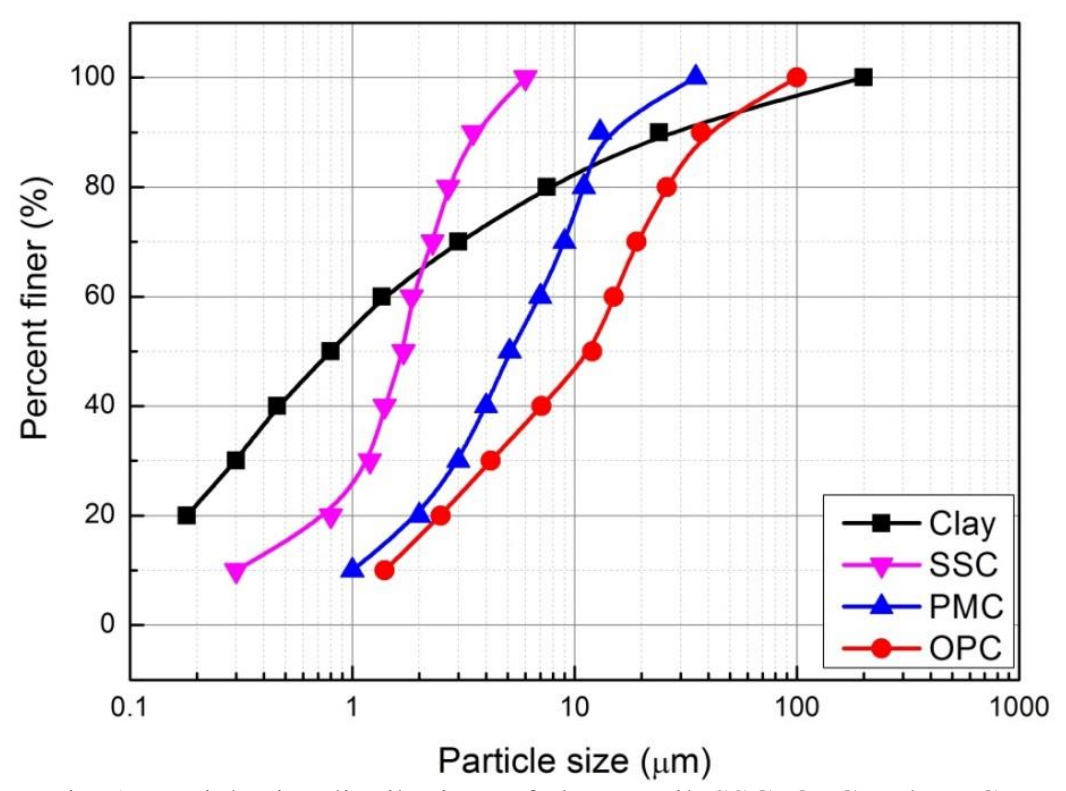

Fig. 1: Particle size distributions of clayey soil, SSC, OPC and PMC. 


\section{OPC, PMC and SSC}

Cements used in this research were Ordinary Portland Cement (OPC), Portland-based Microfine Cement (PMC) under the brand name of Rheocem 650 and superfine slag-based cement (SSC) under the brand name of Spinor A6. Rheocem 650 is a microfine cement milled from pure Portland cement clinker. Spinor A6 is a product of ultra-fine blast furnace slag having a maximum grain size of $6 \mu \mathrm{m}$. OPC, PMC and SSC particle size distributions were determined by means of Laser Particle size Analyser and shown in Fig. 1. The grain size distribution of high plasticity clayey soil was also given in Fig. 1 as a comparison. As seen from the figure, the particle sizes of SSC were much smaller than those of OPC and PMC. Table 2 summarized some physical and chemical properties of above mentioned cements. While PMC and OPC have chemical composition in common, SSC differs from them in that regard. As the calcium oxide in SSC is $45 \%$, it is $62.5 \%$ in OPC and PMC. In addition, $\mathrm{SiO}_{2}$ contents in SSC, PMC and OPC are 30\%, 19.8\% and $18.8 \%$ respectively. SSC compared to OPC and PMC is predominantly slag based product and has a specific surface area of $11,800 \mathrm{~cm}^{2} / \mathrm{g}$.

Table 2: Physical and chemical properties of OPC, PMC and SSC.

\begin{tabular}{|c|c|c|c|}
\hline & OPC & PMC & SSC \\
\hline $\mathrm{SiO}_{2}$ & 18.8 & 19.8 & 30.0 \\
\hline $\mathrm{Al}_{2} \mathrm{O}_{3}$ & 4.0 & 4.2 & 9.5 \\
\hline $\mathrm{Fe}_{2} \mathrm{O}_{3}$ & 5.3 & 4.1 & 1.25 \\
\hline $\mathrm{CaO}$ & 62.2 & 62.5 & 45.0 \\
\hline $\mathrm{MgO}$ & 2.0 & 2.8 & 5.6 \\
\hline $\mathrm{SO}_{3}$ & 3.25 & 2.1 & - \\
\hline $\mathrm{D}_{50}(\mu \mathrm{m})$ & 12 & 5.1 & 1.7 \\
\hline $\mathrm{D}_{95}(\mu \mathrm{m})$ & 60 & 11.2 & 4.0 \\
\hline Specific Gravity & 3.19 & 3.10 & 3.94 \\
\hline Fineness $\left(\mathrm{cm}^{2} / \mathrm{g}\right)$ & 3,836 & 6,250 & 11,800 \\
\hline
\end{tabular}

\section{Specimen preparation}

The contents of OPC, PMC and SSC were based on the dry weight of clayey soil in the mixture. OPC, PMC and SSC percentages in the stabilized clayey soil specimens were 8,10 and 12. The high plasticity clayey soil was mechanically mixed with the required amount of cement homogeneously. After that the pre-determined amount of water was added to the mixture and the whole components were thoroughly blended once more and made ready for the following tests.

\section{Consistency limits}

The consistency limits of clayey soil and cement stabilized clayey soil specimens were determined with reference to ASTM D4318-10e1 (2010) standard [17], the results of which were given in Fig. 2.
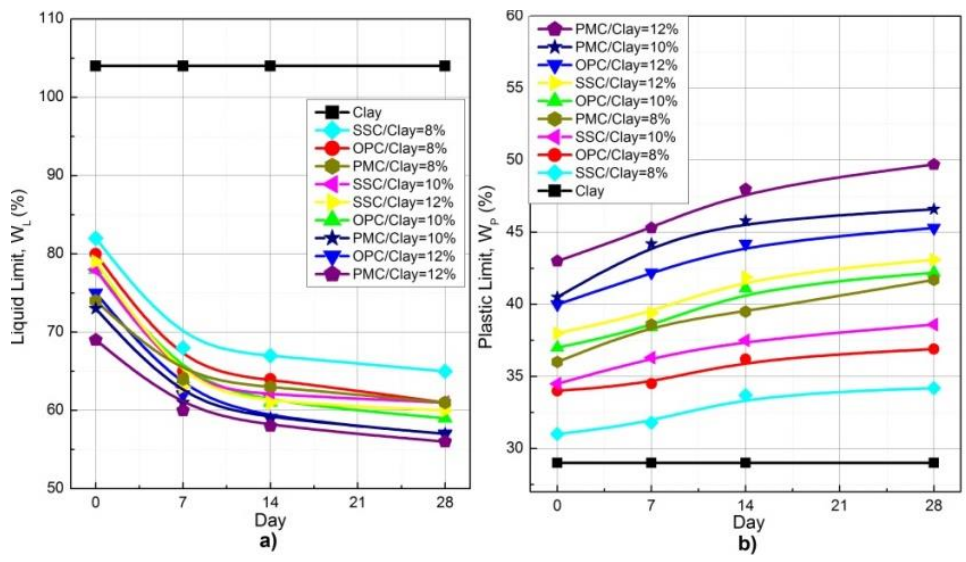

Fig. 2: Behaviour of consistency limit with time. 


\section{Compaction test}

Maximum dry unit weights of OPC, PMC and SSC stabilized clayey soil mixtures were determined by standard compaction tests [20]. At first, dry cements were mechanically mixed with dry clayey soil before compaction until homogenous mixtures were obtained. The mixtures were then mixed with a pre-determined amount of water for the first compaction effort. After that, compacted samples taken out of moulds were broken into small pieces and remixed with an additional necessary amount of water for each succeeding compaction effort. The whole compaction process was completed within 45 minutes to avoid the hardening of clay-cement mixture. The compaction test results were shown in Fig. 3.

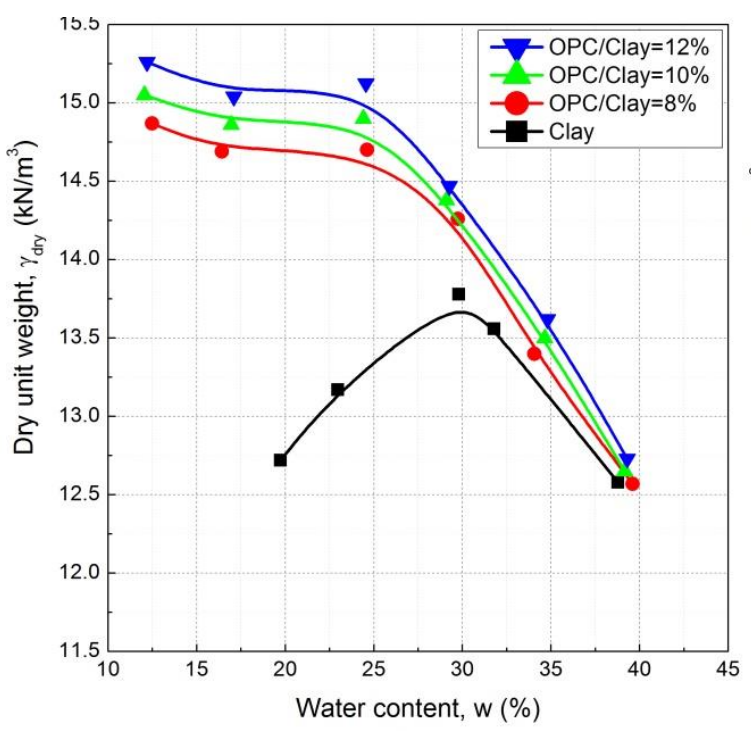

a)

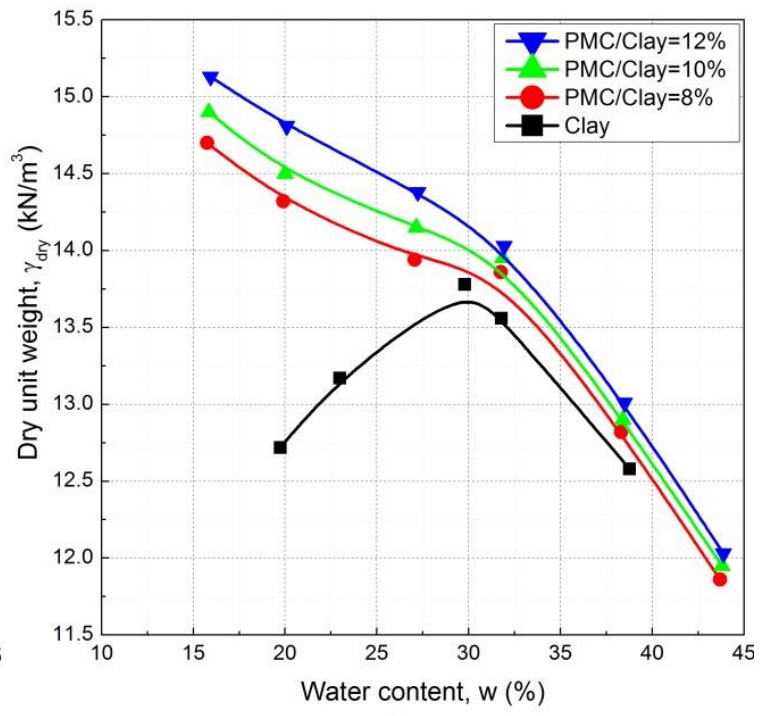

b)

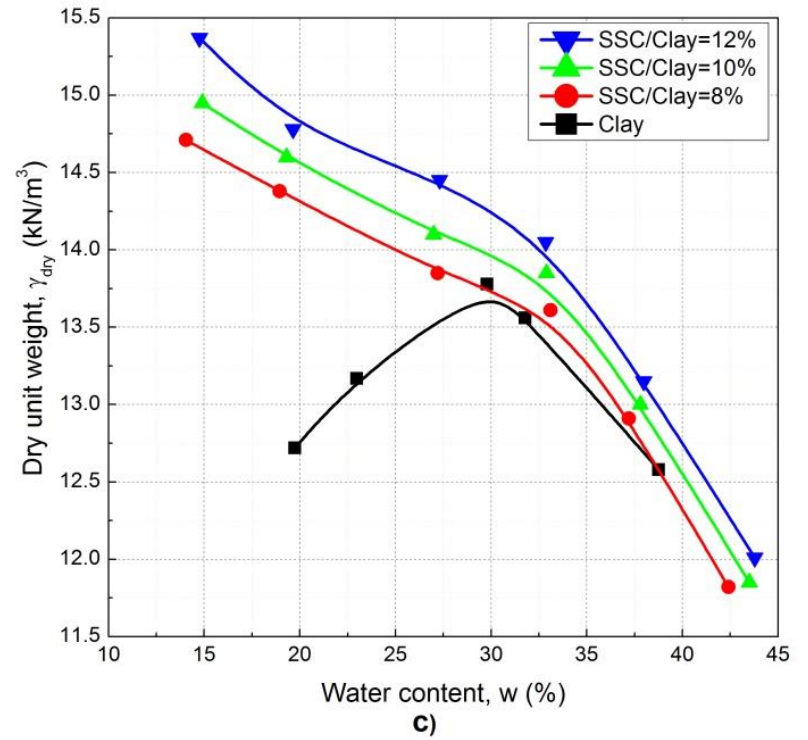

Fig. 3: Compaction curves for OPC, PMC and SSC stabilized clayey specimens.

\section{Swelling test}

Samples needed for swelling tests were obtained from compaction test specimens by means of consolidometer rings. The swell potential of clayey soil and the samples treated with different percentages of OPC, PMC and SSC were measured by conducting swell-consolidation tests with reference to ASTM D 4546 (2008) [21]. OPC, PMC and SSC Stabilized clayey samples were kept in resealable plastic bags in a humidity room of $20{ }^{\circ} \mathrm{C}$ for 28 days and then subjected to swelling tests. The swell potentials of OPC, PMC and SSC stabilized clayey soil specimens were given in Table 3. 
Table 3: Swell potentials of stabilized clayey soil specimens.

\begin{tabular}{|c|c|}
\hline & $\begin{array}{c}\text { Swell potential } \\
(\%)\end{array}$ \\
\hline clay & 9.82 \\
\hline OPC/clayey soil=8\% & 0.35 \\
\hline OPC/clayey soil $=10 \%$ & 0.25 \\
\hline OPC/clayey soil $=12 \%$ & 0.15 \\
\hline PMC/clayey soil $=8 \%$ & 0.30 \\
\hline PMC/clayey soil $=10 \%$ & 0.15 \\
\hline PMC/clayey soil $=12 \%$ & 0.10 \\
\hline SSC/clayey soil $=8 \%$ & 0.45 \\
\hline SSC/clayey soil $=10 \%$ & 0.35 \\
\hline SSC/clayey soil $=12 \%$ & 0.20 \\
\hline
\end{tabular}

\section{Compressibility test}

Specimens for compressibility tests were also procured from compaction test specimens through consolidometer rings. They were placed in resealable plastic bags and let to cure for 28 days in a humid room of $20{ }^{\circ} \mathrm{C}$. After curing, each specimen was removed from the plastic bags and put into the consolidometer cells with filter papers and porous stones on both ends of the specimen. The specimens' moisture content losses during swell tests were prevented by filling odometer cells with water. Thereafter, compressibility tests were run in accordance with ASTM D4546 (2008) standard and the test results were shown in Fig. 4 [21].
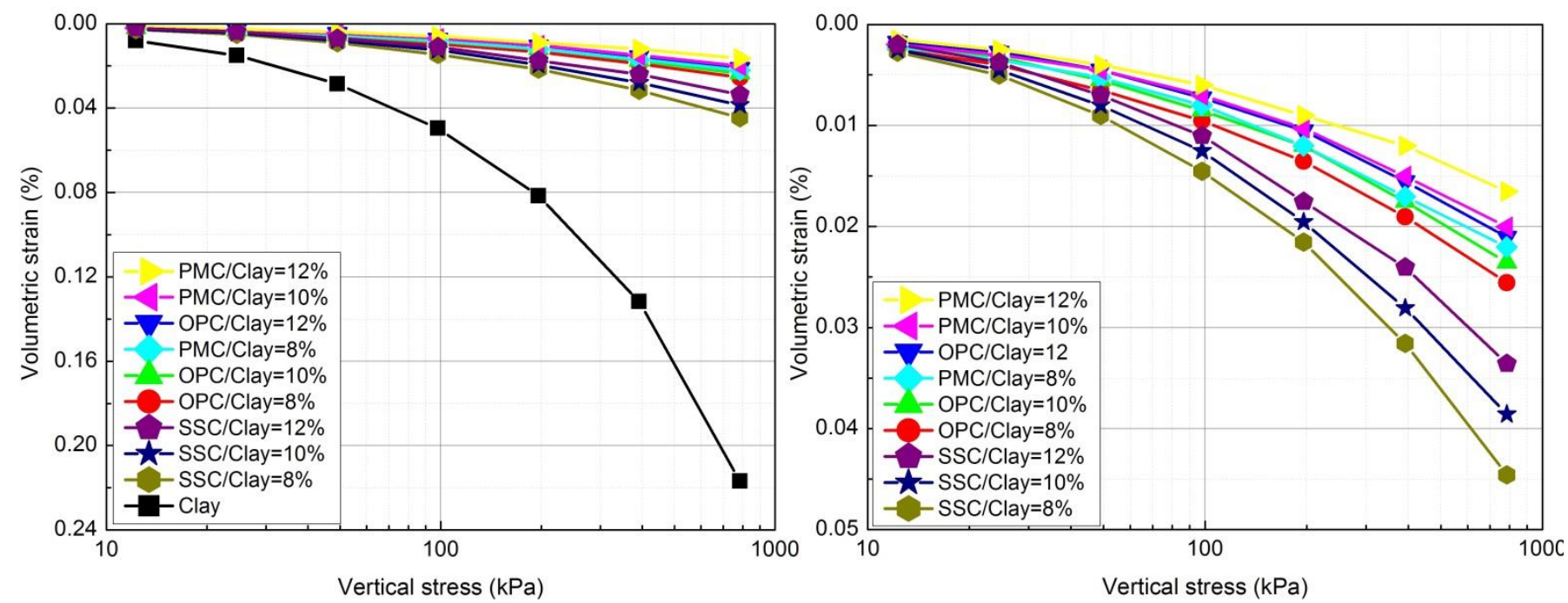

Fig. 4: Compressibility characteristics of OPC, PMC and SSC stabilized clayey soil specimens.

\section{Results and Discussion}

\subsection{Consistency limits}

The liquid limit of clayey soil was reduced with OPC, PMC and SSC stabilizations with time. It was reported that divergent trends for two soils, with the more plastic soil (containing montmorillonite) showing a significant decrease in liquid limit after 7 day curing, and a less plastic soil showing a corresponding increase [22]. The general trend appears to be one of decreased liquid limit if the untreated soil was highly plastic and increased liquid limit in soil of low plasticity. At the end of 28 day curing period, while the plastic limit values of all contents of PMC and OPC stabilized clayey soils 
were higher than that of host clayey soil. It was suggested that one possible reason for this increase is aggregation and cementation of particles into larger size clusters [23]. Another possible reason is the water trapped within intra-aggregate pores. The presence of this intra-aggregate water increases the apparent water content without really affecting interaction between aggregates [24]. While the highest liquid limit value was obtained from SSC stabilized clayey soil specimens, PMC stabilized clayey soil specimens resulted in the lowest liquid limit value. Similarly, as PMC stabilized clayey soil specimens lead to the highest plastic limit value, SSC stabilized clayey soil specimens yielded to the lowest plastic limit value. In general, as the percentage of cement increased, liquid limit decreased and plastic limit increased. Similar findings were also reported by other researchers [25]. Furthermore, though OPC and PMC have similar chemical composition, PMC with finer particles were more effective in further decreasing liquid limit and increasing plastic limit than OPC. SSC having the finest particles among other cements was not as effective as PMC since it was mainly slag-based cement with much less $\mathrm{CaO}$ content.

\subsection{Compaction characteristics}

It was not possible to obtain the Characteristic compaction curve for cement stabilized clayey soil specimens. For this reason, optimum moisture content (OMC) of host clayey soil was used as a criterion for the addition of cement to clayey soil specimens and then compaction tests were carried out accordingly. It was observed that the dry unit weight of clayey soil was increased with the increase of OPC, PMC and SSC contents (Fig. 3). Similar findings were also reported earlier [25-27]. Nevertheless, the dry unit weights of PMC and SSC stabilized specimens were lower than those of OPC stabilized samples. This may be owing to the fact that as the specific surface area increases, hydration reaction increases leading to more flocculation of the clay particles thus increasing the porosity of the clay matrix.

\subsection{Swell potential}

The swell percentage of host clayey soil samples preserved in resealable plastic bags for 28 days was about 9.82 percent (Table 3). While the swell percentage of OPC stabilized clayey soil specimens were in the range of $0.35 \%$ and $0.25 \%$, the swell percentage of PMC stabilized clayey soil specimens were in between $0.30 \%$ and $0.10 \%$. In addition, the swell percentage of SSC stabilized specimens ranged from $0.45 \%$ to $0.20 \%$. In general, OPC, PMC and SSC stabilizations reduced the swell potential of high plasticity clayey soil significantly. Zhao et al. (2013) reported that swelling of high plasticity clay dropped greatly with curing time and almost lost swelling property after 7 day curing period [28]. The swell potential of high plasticity clayey soil was further reduced with the increase in OPC, PMC and SSC cement contents (Table 3). As the PMC stabilization brought about the lowest swell potential, SSC stabilization yield to the highest swell potential. Addition of Portland cement reduces the swelling potential of the improved clay [29]. Even though OPC and PMC have similar chemical composition, PMC with finer particles were more effective in further decreasing swelling potential than OPC. However, SSC having the finest particles among other cements was not as effective as PMC. This may be due to the higher $\mathrm{CaO}$ content of PMC causing a binding force between clay particles in addition to its fineness.

\subsection{Compressibility}

The total compressibity of high plasticity clayey soil compacted at its OMC was about 21.7 percent as seen in Fig. 4. As the total compressibility of OPC stabilized clayey soil specimens were in between $2.7 \%$ and $2.1 \%$, the total compressibility of PMC stabilized clayey soil specimens were in between $2.2 \%$ and $1.6 \%$ and that of SSC stabilized clayey soil specimens were in the range of $4.4 \%$ and $3.3 \%$. The compressibility of high plasticity clayey soil was reduced tenfold, elevenfold and sixfold by OPC, PMC and SSC stabilizations respectively. Further increase in OPC, PMC and SSC contents slightly reduced the compressibility of stabilized clayey soil specimens. The compressibility of clayey soils was effectively improved by cement stabilization [30-33]. The compressibility of SSC stabilized specimens was slightly higher than those of OPC and PMC stabilized clayey soil specimens. In addition, the compressibility of PMC stabilized clayey soil specimens were slightly lower than those of OPC stabilized specimens. Even though OPC and PMC have similar chemical composition, PMC with finer particles was more effective in further decreasing compressibility than OPC. On the

other hand, SSC having the finest particles among other cements was not as effective as PMC. This may be because of the fact that $\mathrm{SSC}$ contains less $\mathrm{CaO}$ content needed for hydration as well as pozzolanic reaction. 


\subsection{Possible errors associated with the results}

It should be born in mind that temperature variation, curing condition, precision of the contents of materials used and laboratory technicians in carrying out tests are all factors in effecting test results.

\section{Conclusion}

The main conclusions of this research are as follows:

- The liquid limit of high plasticity clayey soil is reduced with all contents of OPC, PMC and SSC stabilizations with time. While the plastic limit values of all contents of PMC and OPC stabilized clayey soils are higher than that of host clayey soil.

- As the cement content increases, the dry unit weight of host clayey soil increases whether the cement type used is OPC, PMC or SSC. In addition, the dry unit weights of SSC and PMC stabilized specimens are lower than those of OPC stabilized samples.

- OPC, PMC and SSC stabilizations reduces the swell potential of high plasticity clayey soil significantly. In addition, the swell potential of high plasticity clayey soil is further reduced by the increase in OPC, PMC and SSC cement contents. As the PMC stabilization brings about the lowest swell potential, SSC stabilization yields to the highest swell potential.

- The compressibility of host clayey soil is significantly reduced by OPC, PMC and SSC stabilizations. Increase in OPC, PMC and SSC contents slightly decreases the compressibility of stabilized specimens. The compressibility of SSC stabilized specimens is slightly higher than those of OPC and PMC stabilized clayey soil specimens. In addition, the compressibility of PMC stabilized clayey soil specimens are slightly lower than those of OPC stabilized specimens.

- Although OPC and PMC have similar chemical composition, PMC is more effective in decreasing compressibility and swell potential than OPC. SSC having the finest particles among other cements is not as effective as PMC.

- It is observed that fine-grained cement would be more effective than those with coarser particles in the volume change control of high plasticity clayey soils. Furthermore, Fine-grained cements with higher $\mathrm{CaO}$ content seem to be more effective.

\section{References}

[1] J. D. Nelson, R. D. Miller, Expansive soils: problems and practice in foundation and pavement engineering. John Wiley and Sons, New York, 1992.

[2] C. S. Gourly, D. Newill, H. D. Schreiner, "Expansive soils: TRL's research strategy," in Proceedings of the 1st international symposium on engineering characteristics of arid soils, Balkema, London, pp. 247-260, 1994.

[3] S. Bhattacharja and J. I. Bhatty, Comparative performance of Portland cement and lime in stabilization of moderate to high plasticity clay soils. IIIinois, Portland Cement Association, 2003.

[4] D. T. Bergado, L. R. Anderson, N. Miura, A. S. Balasubramaniam, Soft Ground Improvement in Lowland and Other Environments. ASCE, New York, 1996.

[5] S. H. Chew, A. H. M. Kamruzzaman and F. H. Lee, "Physicochemical and engineering behavior of cement treated clays," Journal of Geotechnical and Geoenvironmental Engineering, vol. 130, no. 7, pp. 696-706, 2004.

[6] F. G. Bell, "Influence of the mineral content of clays on their stabilization by cement," Bulletin of the Association of Engineering Geologists, vol. 13, no. 4, pp. 267-278, 1976.

[7] T. M. Petry and S. Kelly, Effects of pulverization on the strength and durability of highly active clay soils stabilized with lime and Portland cement. Transportation Research Board, U.S., 1988.

[8] F. Lasisi, and A. M. Ogunjide, "Effect of grain size on the strength characteristics of cement stabilized lateritic soils," Building and Environment, vol. 19, no. 1, pp. 49-54, 1984.

[9] F. G. Bell, "Assessment of cement-PFA and lime-PFA used to stabilize clay-size materials," Bulletin of the International Association of Engineering Geology, vol. 49, pp. 25-32, 1994.

[10] J. R. Prusinski and S. Bhattacharja, "Effectiveness of Portland cement and lime in stabilizing clay soils," Transport. Res. Rec., vol. 1652, pp. 215-227, 1999.

[11] L. N. Mohammad, A. Raghavandra and B. Huang, "Laboratory performance evaluation of cement-stabilized soil base mixtures," Transport. Res. Rec., vol. 1721, pp. 19-28, 2000. 
[12] A. W. Hago, A. A. Al-Rawas and A. Al-Riyami, "Effect of varying cement content and curing conditions on the properties ofsarooj (artificial pozzolana)," Building and Environment, vol. 37, pp. 45-53, 2002.

[13] D. L. Druss, "Guidelines for design and installation of soil-cement stabilization," Geotech. Special Pub., vol. 120, pp. 527-539. 2003.

[14] D. Wang, N. E. Abriak and R. Zentar, "Strength and deformation properties of Dunkirk marine sediments solidified with cement, lime and fly ash," Engineering Geology, vol. 166, no. 8, pp. 90-99, 2013.

[15] A. Ahmed, "Compressive strength and microstructure of soft clay soil stabilized with recycled bassanite," Applied Clay Science, vol. 104, pp. 27-35, 2015.

[16] ASTM D 422-63, Standard test method for particle-size analysis of soils. Annual Book of ASTM Standards, West Conshohocken, PA, 2002.

[17] ASTM D 4318-10e1, Standard test methods for liquid limit, plastic limit, and plasticity index of soils. Annual Book of ASTM Standards, West Conshohocken, PA, 2010.

[18] ASTM D 854-02, Standard test method for specific gravity of soil solids by water pycnometer. Annual Book of ASTM Standards, West Conshohocken, PA, 2002.

[19] ASTM D 2487-00, Standard practice for classification of soils for engineering purposes (unified soil classification system). Annual Book of ASTM Standards, West Conshohocken, PA, 2002.

[20] ASTM D 698-00a, Standard test methods for laboratory compaction characteristics of soil using standard effort $(12,400 \mathrm{ft}-\mathrm{lbf} / \mathrm{ft} 3(600 \mathrm{kN}-\mathrm{m} / \mathrm{m} 3))$. Annual Book of ASTM Standards, West Conshohocken, PA, 2000.

[21] ASTM D 4546-08, Standard Test Methods for One-Dimensional Swell or Collapse of Soils, Annual Book of ASTM Standards. West Conshohocken, PA, 2008.

[22] H. Brandl, "Alteration of soil parameters by stabilization with lime," in Proceedings of 10th International Conference on Soil Mechanics and Foundation Engineering, Stockholm, 1981, vol. 3, pp. 587-594.

[23] J. Locat, M. A. Berube and M. Choquette, "Laboratory investigation on the lime stabilization of sensitive clays: Shear strength development," Can. Geotech. J., vol. 27, no. 3, pp. 294-304, 1990.

[24] J. Locat, H. Tremblay, S. Leroueil, "Mechanical and Hydraulic Behavior of a Soft Inorganic Clay Treated with Lime," Can. Geotech. J., vol. 33, no. 4, pp. 654-669, 1996.

[25] S. Horpibulsuk, R. Rachan, A. Chinkulkijniwat, Y. Raksachon and A. Suddeepong, "Analysis of strength development in cement-stabilized silty clay from microstructural considerations," Construction and Build Materials, vol. 24, no.10, pp. 2011-2021, 2010.

[26] D. N. Richardson, "AASHTO layer coefficients for cement-stabilized soil bases," Journal of Materials in Civil Engineering, vol. 8, no. 2, pp. 83-87, 1994.

[27] M. Aniculăesi, A. Stanciu, I. Lungu, "Behavior of expansive soils treated with ecocement," Bulletin of the Polytechnic Institute of Iasi-Construction \& A LVII (LXI) (f. 2), pp. 9-19, 2011.

[28] H. Zhao, Z. Chun-Ji, Z. Xiao and L. Chan, "Physicochemical characterization of cement stabilized highly expansive clay," In Proceedings of Geo-Congress 2013: Stability and Performance of Slopes and Embankments III, San Diego, California, 2013, pp. 2084-2093.

[29] S. Bhattacharja, J. I. Bhatty and H. A. Todres, Stabilization of Clay Soils by Portland Cement or Lime- A Critical Rewiew of Literature. IIIinois, Prtland Cement Association, 2003.

[30] H. Tremblay, S. Leroueil and J. Locat, "Mechanical improvement and veritcal yield stress prediction of clayey soils from eastern Canada treated with lime or cement," Can. Geotech. J., vol. 38, no. 3, pp. 567-579, 2001.

[31] G. V. Rotta, N. C. Consoli, P. D. M. Prietto, M. R. Coop and J. Graham, "Isotropic yielding in an artificially cemented soil cured under stress," Geotechnique, vol. 53, no. 5, pp. 493-501, 2003.

[32] S. Horpibulsuk, D. T. Bergado and G. A. Lorenzo, "Compressibility of cement-admixed clays at high water content," Geotechnique, vol. 54, no. 2, pp. 151-154, 2004.

[33] S. Rios, A. Vianna da Fonseca and B. Baudet, "Effect of the porosity/cement ratio on the compression of cemented soil," Journal of Geotech. and Geoenviromental Engineering, vol. 138, no. 11, pp. 1422-1426, 2012. 